\title{
Effect of an Illustrated Educational Guide on Anxiety Level among Parents of Children Undergoing Cardiac Catheterization
}

\author{
Awatif Aly Hassan Elsharkawy, Lecturer \\ Pediatric Nursing, Faculty of Nursing, Alexandria University \\ Shadia Ramadan Morsy, Lecturer \\ Nursing Education, Faculty of Nursing, Alexandria University
}

\begin{abstract}
Cardiac catheterization is a stressful and anxiety induced experience for parents of children prior to cardiac catheterization. Thus, the responsibilities of a catheterization lab nurse begin with the assessment of parental anxiety as a part of pre-procedure preparation of parents. There is an evidence that information offered by CCL pediatric nurses pre-procedure reduces parental anxiety. Information can be provided by a variety of methods. In this study, it was provided by a printed material such as illustrated educational guide. Objective: The aims of the study are to develop an illustrated educational guide about pediatric cardiac catheterization and evaluate its effectiveness on anxiety level in parents of children undergoing cardiac catheterization. Setting: This study was conducted at Cardiac Catheterization Lab, Makassed General Hospital (MGH) Beirut, Lebanon. Subjects: It comprised of a convenience sample of 100 parents (father or mother). Parents were randomly allocated into two groups. The control group was educated by using conventional verbal information method while, the study group was educated by both verbal and use the illustrated educational guide about pediatric cardiac catheterization. Tools: Two tools were used for data collection; Beck Anxiety Inventory (BAI) and the Illustrated educational Guide about Pediatric Cardiac Catheterization. Results: During pre-orientation phase, It was found that the highest percent of parents (74\% in the study group and $68 \%$ in the control group) experiencing moderate anxiety before giving information either by using the informative guide about cardiac catheterization or verbally. Whereas, during post orientation phase, it was obviously noticed that the majority of parents (90\%) in the study group exhibit low anxiety level after receiving information about cardiac catheterization using illustrated educational guide, compared to $40 \%$ of parents in the control group who received the information verbally. Conclusion: The results of the study denote using of a developed illustrated educational guide about pediatric cardiac catheterization was effective in reduction of anxiety level among parents. Recommendations: Cardiac catheterization nurses should develop an illustrated educational guide about cardiac catheterization to be used as a reference for orientation pre-cardiac catheterization procedure and disseminated to parents before discharge.
\end{abstract}

Keywords: Pediatric cardiac catheterization; Parent anxiety; Educational guide.

\section{Introduction}

Congenital Heart Disease (CHD) is the most well-known inborn anomaly in newborns. Likewise, it is a main etiology of death in the first year of life. It has been defined as the presence of structural abnormality in the heart or great blood vessels during intrauterine life. The exact cause of $\mathrm{CHD}$ is obscured nevertheless rapid and recent advances thought that it is due to multifactor as complex interaction of genetic and environmental influences ${ }^{(1,2)}$. Congenital Heart Diseases are commonly found in the pediatric age group from 0 to 15 years $^{(3)}$. Congenital heart defects may be classified intocyanotic and a-cyanotic depending upon whether the patients clinically exhibit cyanosis ${ }^{(4)}$. 
Congenital Heart Disease can affect any child, regardless of nationality or socioeconomic background. Worldwide, it accounts for 8-12/1000 live births and approximately $30 \%$ to $40 \%$ of all congenital defects $^{(5)}$. Annually, in Lebanon alone 1 in 100 babies is born with Congenital Heart Disease. More than 700 babies are diagnosed with heart disease every year ${ }^{(6)}$. While in Alexandria (Egypt), it was found the prevalence of congenital heart diseases (CHD) among school children accounted for $1.01 / 1000$ child $^{(7)}$. In United States, the incidence of CHD ranges between 4$10 / 1000$ live births ${ }^{(8)}$. Currently, with great advancements in prenatal diagnosis and corrective strategies, the number of infantile deaths has declined, and more than $3 / 4$ of children with congenital malformations survive into adulthood ${ }^{(9)}$.

A variety of invasive and noninvasive techniques may be implemented in diagnosis of congenital heart diseases among children. Pediatric cardiac catheterization is the most invasive diagnostic procedure which is usually required prior to therapeutic intervention. In the last two decades, remarkable medical progresses allow congenital heart defects to be treated in the catheterization lab without surgery. Pediatric cardiac catheterization is a sterile procedure performed using a radiopaque catheter that is inserted through a peripheral blood vessels into the heart. It is usually combined with angiocardiography in which a radiopaque contrast material is injected through the catheter and into the circulation. Pediatric cardiac catheterization provides information regarding oxygen saturation of blood within heart chambers and great vessels, cardiac output or stroke volume as well as anatomic abnormalities such as septal defects or obstruction ${ }^{(10-12)}$.

Pediatric cardiac catheterization may be performed for diagnostic, interventional correction or for electrophysiological purpose. Diagnostic cardiac catheterization includes two techniques as right sided or venous catheterization and left sided or arterial catheterization. Whereas the interventional cardiac catheterization is the use of a catheter to treat heart disease such as the use of balloon catheter to dilate narrowed valve or vessels. On the other hand, diagnostic electrophysiological catheterization employs catheter with tiny electrodes that record the heart electrical impulses directly from the conduction system $^{(12-14)}$.

Cardiac catheterization is a stressful and anxiety provoking experience for parents of children during preprocedure $^{(10,15)}$. Uzgeret et al. (2015) found that cardiac catheterization with angiography was associated with increased levels of depression and anxiety in parents of children undergoing cardiac catheterization $^{(1)}$. Woolf - King et al. (2017) reviewed published data in cardiac, nursing, pediatric and social science journals between 1984 and 2015 in the United States from 10 countries (Australia, Switzerland, Norway, the Netherlands, the United Kingdom, Canada, China, Finland and Italy). The researchers found $25 \%$ to $50 \%$ of parents of children with critical congenital heart defects reported elevated symptoms of anxiety, depression or both; and $30 \%$ to $80 \%$ reported experiencing severe psychological distress ${ }^{(16)}$.

Stress and anxiety are fight-and-flight instincts for responding to emergencies. It is a normal, emotional, reasonable and expected response to real or potential danger. Occasional anxiety is a normal part of life. It is a subjective feeling of tension, discomfort, apprehension or fearful concern accompanied by autonomic and somatic manifestations ${ }^{(17)}$. Parental anxiety due to children cardiac catheterization results from numerous reasons such as insufficient information about cardiac catheterization, its procedure, pre-procedure preparation and post procedure management, in addition to the probable complications during or after the procedure as well as follow-up plan of care ${ }^{(18)}$. 
Cardiac catheterization lab pediatric nurses play a pivotal role in cardiac care of children. It is well known that the behavior of children is influenced by the mental health of their parents. Certainly, pediatric cardiac catheterization is recognized as anxiety induced procedure for parents. Thus, the responsibilities of a catheterization lab nurse begin with the assessment of parental anxiety as a part of pre-procedure preparation of parents as well as children for cardiac catheterization. When, cardiac catheterization lab pediatric nurses offer pre-procedure information, it reduces parental anxiety. Giving information should be individualized on the basis of their cultural and intellectual background, their previous hospital experience and knowledge ${ }^{(18-20)}$.

Variety of educational materials can be used to increase parental information and awareness about cardiac catheterization procedure. One of these is the written or printed material which can include booklets, leaflets, pamphlets and informational guides $^{(21,22)}$. Printed materials are the most common educational tool used by cardiac catheterization lab pediatric nurses for many reasons. They allow retention for more information and recalling it at any time. They offer message consistency and allow flexibility in the timing and delivery of information. It makes parents able to refer to them when required and to use them to learn at their own pace. They also are simple and easy to carry and interact with as needed without the necessity of further equipment. In addition to its effectiveness in changing knowledge, attitudes and behavior in relation to a wide range of health-related issues ${ }^{(23-26)}$.

In this study, the researchers developed an illustrated educational guide that contains essential and accurate information about cardiac catheterization procedure, pre and post procedure preparation as well as discharge plan. The information was written in a clear, concise, and simple language. It was accompanied by simple illustrations that are clearly labeled to facilitate comprehension of written information. This guide was developed to equip the parents with the necessary instruction about pediatric cardiac catheterization procedure in a way that increase their awareness and decrease their anxiety regarding it $^{(27)}$.

\section{Aims of the Study}

The aims of the study are to:

1- Develop an illustrated educational guide about pediatric cardiac catheterization.

2- Evaluate the effectiveness of an illustrated educational guide on anxiety level among parents of children undergoing cardiac catheterization

\section{Research Hypothesis:}

Using an illustrated educational guide is more effective than conventional verbal information method in reducing anxiety among parents of children undergoing cardiac catheterization.

\section{Materials and Method}

\section{Materials}

Design: A quasi experimental research design was implemented.

Setting: This study was conducted at Cardiac Catheterization Lab, Makassed General Hospital (MGH) Beirut, Lebanon.

Subjects: It comprised of a convenience sample of 100 parents (father or mother) with the following criteria:

1- Has child with congenital heart disease.

2-The child is undergoing cardiac catheterization for the first time.

Parents were randomly allocated into two groups: control and study group.

Orientation about pediatric cardiac catheterization was given to the control group using conventional verbal method while, the study group received the same 
information during orientation using illustrated informative guide.

\section{Exclusion Criteria:}

Any parent has the following problems was excluded:

- With visual or hearing problems.

- With history of psychological disorders or taking antipsychotic medications.

Tools: Two tools were used for data collection:

\section{Tool I: Beck Anxiety Inventory (BAI)}

This tool was developed by Beck ${ }^{(28)}$. It was adopted and translated into Arabic. It is a self-report measure of anxiety. It is composed of 21 items. The total score is calculated by finding the sum of the 21 items. All questions are ranked as follow not at all $=0$, mildly but it did not bother me much $=1$, moderately- it was not pleasant at times $=2$, severely- it bothered me a lot $=3$. The total score is calculated by finding the sum of the 21 items.

Score of $0-9=$ Minimal anxiety

Score of 10-16= Mild anxiety

Score of $17-29=$ Moderate anxiety

Score of $30-63=$ Severe anxiety

There are attached data regarding parents' biosocio-demographic characteristics included in this tool such as age, sex, marital status, and level of education.

Besides, children's characteristics include age, gender, birth order, and diagnosis.

\section{Tool II: The Illustrated educational} Guide about Pediatric Cardiac Catheterization

This illustrated educational guide was developed by the researchers after thorough reviewing of the current and related literature as well as it included the conventional information which was given to all parents from the nursing and medical staff of the Cardiac Catheterization Department in the hospital to guarantee that all parents in both groups received the same information. It included definition of cardiac catheterization, indications, types, cardiac catheterization lab, pre-procedure preparation of the child, and intervention during cardiac catheterization procedure, post procedure management of the child undergoing cardiac catheterization, discharge plan for the child and finally the probable complications of cardiac catheterization for the child.

\section{Method}

- An official permission to conduct the study was obtained from the responsible authorities in institutional review board (IRB) of Makassed General Hospital (MGH).

- Tools I was adopted and translated into Arabic. The accuracy of its translation was reviewed and validated by a jury of five expertises in nursing and related field of psychology.

- Development of Tool II "The illustrated educational guide about pediatric cardiac catheterization" (attached booklet)done through three phases which includes:

a. Preparation phase: The researchers achieved it after reviewing the related and current literature about pediatric cardiac catheterization. It was also congruent with the conventional verbal instructions that were given by cardiac catheterization lab staff in the previous mentioned setting. It displays the objectives of the guide, definition of cardiac catheterization, its indications and duration and pre, intra and post procedure interventions as well as discharge instructions:

- Pre-procedural preparation of the child that includes the following: nothing per mouth (NPO), wearing the apron, taking vital signs and growth measurement, asking about the presence or absence of allergy on iodine, medication or 
food, inserting an intravenous line, signing the informed consent of the parent, and taking the preprocedural medication.

- Intra-procedure interventions on the cardiac lab environment include lying supine during the procedure, attaching the child to the monitor, taking general anesthesia, the insertion of the catheter, showing the pathway from the artery of the extremity to the coronary arteries, and heart, injection of the dye.

- Post-procedural interventions as pressing on the insertion site for 20 - 30 minutes, applying a tense plaster around the site, returning to the patient's room, giving the instructions that the patient must keep his affected extremity straight for a period of time, continuous assessment by the nurse of the peripheral circulation, the color and the pulse of that extremity, being able to take fluids post-procedure if the condition permits, and being able to know the result of the procedure.

- Discharge instructions about cleanliness of insertion site, measures to control bleeding if occurred, manifestations of infection or inflammation in insertion site of the catheter, bathing precautions and play instructions.

- The content validity of the illustrated educational guide was tested and reviewed by five expertise in the field of nursing and staff in cardiac catheterization lab.

- Interview was conducted with parents (for both groups) in the child's room at hospital upon admission at least 2 hours before cardiac catheterization.
- During this interview, parents and children demographic data, health related characteristics and anxiety level were assessed using tool I.

b. Orientation phase / implementation phase: involve the following steps:

- A pilot study was carried out on a sample of ten parents not included in the study, in order to test the feasibility, clarity, and applicability of the study tools, and accordingly, little modifications were done that include removal of some sophisticated images about intra procedural technique of cardiac catheterization.

- A convenience sample of parents who have child undergoing cardiac catheterization for the first time were randomly allocated into two groups. Firstly, data was collected from parents in the control group.

- The orientation about information of pediatric cardiac catheterization was implemented as follow:

- The information about pediatric cardiac catheterization was delivered verbally by the researcher for parents in the control group (which is the conventional method used in the cardiac catheterization unit)

- The study group was received the information about pediatric cardiac catheterization by the researcher using both verbal explanations and the illustrated educational guide.

- Parents in both groups were encouraged to ask for further information for more explanation if needed.

c. Evaluation phase: included the following: 
- After giving information and while waiting for the child cardiac catheterization to be done, about 30 minutes before the procedure, the anxiety level of parent was assessed again using tool I.

- Both verbal and using educational guide sessions lasted from 30- 40 minutes.

- Data collection started from March 2016 to August 2016.

\section{Ethical considerations:}

- Informed written consent for voluntary participation in the study was obtained from the recruited patients and their family caregivers after explaining the aim of the study.

- Subjects' privacy and anonymity were assured and respected.

- Data confidentiality was considered and respected.

\section{Statistical Analysis}

- Collected data were coded and transferred into specially designed formats suitable for computer feeding.

- Data entry, checking and verification were carried out. Frequency analysis, cross-tabulation and manual revision were all used to detect any errors.

- The Statistical Package for Social Sciences (SPSS) program, version 20.0 was utilized for both data presentation and statistical analysis of the results.

- The following statistical measures were used:
A. For descriptive presentations frequency, percentage, minimum, maximum, arithmetic mean, and standard deviation were used.
B. Fisher's Exact Test (FET) was used to test the association

$$
\begin{array}{lcr}
\text { between } & \text { variables } & \text { when } \\
\text { expected } & \text { frequency } & >5 \\
\text { exceeding } 20 \% \text { of cells. } &
\end{array}
$$

- Levels of significance selected for this study were $\mathrm{p}$ equal to or less than 0.05 and 0.001 .

\section{Results}

It is noticed in table (1) that the highest percentage of children aged from two to 4 years in both the study and control group. The male gender constitutes nearly the two third of the children in both groups (64\% in study group and $68 \%$ in the control one). The first child represents the highest percent in the study as well as in the control group (76\% and $80 \%$ respectively). The majority of children have a-cyanotic congenital heart diseases (94\% in the study group and $90 \%$ in the control one).

Table (2) shows the biosociodemographic characteristics of the parents. Regarding the age, the highest percent of parents were aged from 30 to less than 40 years in both the study and the control groups (48\% and $46 \%$ respectively). The parents aged less than 25 years were the least in both the study and the control groups $4 \%$ and $10 \%$ respectively.

Concerning the gender of the parents, nearly half of the parents in both the study group and the control group were fathers with $52 \%$ and $54 \%$ respectively.

With respect to the marital status, most of the parents in the study group (94\%) and the control groups (88\%) were married.

Referring to the level of education, the highest percentage of parents in the study group $(42 \%)$ had intermediate education and the least represented parents (10\%) in the same group had elementary education. On the other hand, the highest percentage of the parents (38\%) in the control group had secondary education and the least represented parents $(8 \%)$ in the same group had university degree.

No statistical significant differences were observed between the two groups in 
relation to their age, gender, marital status, and educational level.

Table (3) shows that all parents in both groups exhibit anxiety before giving information about pediatric cardiac catheterization but in different level in which $29 \%$ of them experience mild anxiety while the majority of parents $(71 \%)$ have moderate anxiety level.

Table (4) illustrates comparison between two groups during pre and post orientation of giving information regarding their level of anxiety. During preorientation phase, It was found that the highest percent of parents $(74 \%$ in the study group and $68 \%$ in the control group) experiencing moderate anxiety before giving information either by using the informative guide about cardiac catheterization or verbally. There is no statistical significant difference between two groups.

Whereas, during post orientation phase, it is obviously noticed that the majority of parents $(90 \%)$ in the study group exhibit mild anxiety level after receiving information about cardiac catheterization using illustrated educational guide, compared to $40 \%$ of parents in the control group who received the information verbally. There was statistical significant difference between both groups post orientation phase.

Table (5) represents that in the control group, there are more than two thirds of parents have moderate anxiety before receiving verbal orientation about cardiac catheterization whereas, their percentage are reduced to $60 \%$ after gaining information verbally. The mean score of BAI among parents was $28.1000 \pm 8.14724$ which is declined to 23.9400. \pm 7.45164 after verbal orientation. So there is an evident statistical significant difference $(\mathrm{P}=0.022)$.

Table (6) presents the comparison between the levels of anxiety among parents during pre and post using the informative guide. It was found that nearly three quarter of the parents experiencing moderate anxiety before using the educational guide about cardiac catheterization compared to the majority of them exhibit mild degree of anxiety after using the informative guide. The mean score of BAI among parents was $26.1800 \pm 6.2227$ before using the informative guide which is decreased to 23.9400..77.45164 after using it with statistical significant difference at $\mathrm{P}=0.00$.

Table (7) shows during pre-orientation phase in the study group, about two thirds of parents $(68 \%)$ who have children with acyanotic congenital heart disease exhibit moderate anxiety level. Whereas, after using the illustrated informative guide during orientation, the majority of parents (90\%) who have children with the same diagnosis experience low anxiety. There was a statistical significant difference.

It is noticed in table (8) that in the control group during pre-orientation phase, nearly two thirds of parents $(66 \%)$ who have children with a-cyanotic congenital heart disease exhibit moderate anxiety level. While, after verbal orientation, the percent of parents who have children with the same diagnosis and at the same level of anxiety was reduced to $(58 \%)$.

\section{Discussion}

Pediatric cardiac catheterization is considered as a stressful and anxiety causing experience for children as well as their parents. The child response to the stress of cardiac catheterization will be influenced by many factors such as parents' anxiety that mainly developed due to lack of parents' information about cardiac catheterization procedure and management of child's disease ${ }^{(15)}$. Subsequently, assessment of parental anxiety is so crucial because it contributes to child stress. Correct information about cardiac catheterization should be individualized on the basis of parents' cultural and intellectual background, their previous experience $^{(15,19,29)}$.

Congenital heart defects are commonly found in the pediatric age group from 0 to15 
years ${ }^{(3)}$. The finding of the current study revealed that the age of the child, in both the study and control group and undergoing cardiac catheterization, ranged from neonatal to preschool age (Table 1). This results parallel with the scientific and practical background that prove that cardiac catheterization can be done to children with congenital heart defects at any age even newborns immediately after birth ${ }^{(30)}$.

Regarding the gender, male children in the present study constitutes approximately two third of the sample in both the study and control group (Table 1). The finding in line with researches done in Egypt such as Atwa Z T and Safar H H (2014), their sample included 171 males and 141females with CHDs aged less than 12 years $^{(31)}$. Moreover, In Alexandria, Egypt, Abouheiba MGM (2015) found that the occurrence of congenital heart disease in male children was slightly higher than females ${ }^{(32)}$. It could be due to about $15 \%$ of congenital heart diseases are related with hereditary conditions $^{(1,2)}$.

Regarding the child's diagnosis, the current results denoted that children with acyanotic congenital heart disease represents the majority of children in both the study and control group (table 1). This congruent with Uzger et al. (2015), they found Sixtyone patients $(83.6 \%)$ had a cyanotic congenital heart disease ${ }^{(1)}$. Additionally, in Alexandria, Egypt, Abou heiba MGM (2015) found that the majority of the sample was diagnosed as a-cyanotic congenital heart disease ${ }^{(32)}$.

Parental participation is integral to the preprocedure preparation process of pediatric cardiac catheterization. Family caregivers have a significant responsibility in the care of their child in intensive care ${ }^{(33)}$. Although, the Biosocio-demographic profile of parents in both groups was statistically insignificant, it was appreciated to find during data collection of the current study that both parents (mother and father) present with the child during performance of cardiac catheterization (Table 2). It could be due to that in Lebanon culture, the husband and wife share the authority in child rearing and support, parents spend time with children and are more invested in the treatment process; therefore, children's health problems tend to create anxiety and stress in both parents. Although wives usually have more influence over children and in various household matters ${ }^{(34)}$. Contrary to, Shan $\mathrm{CH}$ and Hawkins $\mathrm{R}$ (2014) finding that mothers were more likely than fathers to be children's fundamental and preferred caregivers ${ }^{(35)}$. It is compatible with Egyptian society that highlight the role of the mother in the family because of carrying out most of household activities including childcare in health and illness ${ }^{(36) .}$

Cardiac catheterization of children is a major reason of anxiety for their parents ${ }^{(37)}$. In the current study, prior to conducting the orientation about pediatric cardiac catheterization either verbally or using the illustrated informative guide, the researcher discovered that all parents in both groups had variable levels of anxiety ranged from mild to moderate as mentioned in table (3). Furthermore, the high percentage of parents in both the study and control group exhibits moderate anxiety level during preorientation phase (Table 4). It could be due to lack of knowledge and accurate information as well as misconception about pediatric cardiac catheterization particularly, this is the first time for all children to perform cardiac catheterization as well as first experience of the parents to confront this situation. Lack of awareness about cardiac catheterization procedure, recovery methods and discharge plan and future life lead to elevation of parents' anxiety ${ }^{(18,38,39)}$. This results parallel with Rahimianfar et al. (2015) findings revealed that stress mean was higher than average among mothers of children undergoing cardiac catheterization ${ }^{(40)}$. Besides, Uzger et al. (2015) results shows BAI scores of parents of children undergoing angiography were $21.9 \%$ had mild, $11 \%$ was moderate, and $17.8 \%$ was severe anxiety ${ }^{(1)}$. Unfortunately, in Lebanon, Zahrlk (2004) assumed that provision of pre-operative 
information on pre and postoperative care is mostly focused on providing procedural information while the psychological needs of children and their parents have rarely been taken into consideration ${ }^{(41)}$.

There is an evidence that the information about the treatment regimen that was offered by nurses at an early stage pre procedure will reduce anxiety ${ }^{(18,42-44)}$. In the current study, it was amazing that after orientation using the illustrated educational guide about pediatric cardiac catheterization, it was found that the majority of parents exhibits reduction of anxiety level from moderate to mild level (Table 4 and 6). It could be due to using of simple and clear information about pediatric cardiac catheterization that increased parent's awareness and leads to decrease their anxiety as well as simple illustration about pre, and post procedure care of the child. This result was supported by Valizadeh et al. (2016), they concluded that using a booklet and film are saving the time, cost, and staffing moreover, sending quick message to large number of people as well as the use of audio-visual equipment helps for better understanding of unfamiliar concepts, when the words unable to express the concepts ${ }^{(45)}$. The results also was congruent with Naylor, Coates , and Kan., they found that using of manuals with coloring books to explain the cardiac catheterization procedure showed less anxiety of parents ${ }^{(46)}$. Furthermore, booklets with color pictures and simple language written could be effective methods of orientation for people with low education. As a result, it could improve the process of communication with staff and increase their participation in the care ${ }^{(47)}$. Contrary, Ayasrah, and Ahmad (2016), Ruffinengo, Versino, and Renga (2009) proved that informative video about pediatric cardiac catheterization leads to reduction of pre-procedural anxiety levels among parents ${ }^{(48,49)}$.

Preprocedure information about cardiac catheterization can be provided by a variety of tools, including printed materials or verbal orientation. All tools reduced patients and parents' anxiety ${ }^{(50)}$.It was noticed in the study group of the current study, that the percentage of parents who have reduction from moderate to mild anxiety was increased after orientation (Table 4, 5 and 6). It may be due to that using of illustrated educational guide and verbal orientation are collaborated and integrated with each other to achieve its effect on reducing parental anxiety While, verbal orientation must be convinced with another educational method. It is congruent with Reberte et al. (2012) who reported that the use of educational booklet in health care is a public practice in the world health system. Furthermore, manuals for health care, guidelines, information leaflets and booklets are able to promote outcomes for educational activities ${ }^{(51)}$. As well Mullin (2015) documented that parent of children undergoing cardiac catheterization sent a home with written instruction ${ }^{(52)}$. Likewise, Kunst, Groot, Latthe, et al. (2002) concluded that the majority of pediatric hospitals that provide surgery and distinctive procedures provide printed material to families. Written materials can be adult or child-directed and are generally enhanced by visual images or diagrams ${ }^{(53)}$.

The present study illustrates that the majority of parents of children who having a-cyanotic congenital heart disease experience anxiety but in variable level ranged between mild to moderate anxiety more than cyanotic one (table 7,8 ). It could be due to small number of children who have cyanotic congenital heart defect. This results is not in line with Uzgaret et al. (2015) who concluded that mothers of patients with cyanotic congenital heart disease had significantly higher levels of depression and anxiety ${ }^{(1)}$.

\section{Conclusion}

Based on the results of the current study, it can be concluded that using the developed illustrated educational guide about pediatric cardiac catheterization was effective in reducing the anxiety level among parents. As it leads to raising the 
parents' awareness about cardiac catheterization procedure, pre-procedure, intra and post-procedure intervention, discharge activities as well as possible complications and feasible management at home. Additionally, there are declining in the level of anxiety when parents received the information verbally.

\section{Recommendations}

Based on the previous results, the following can be recommended:

- Cardiac catheterization nurses should develop and use an illustrated educational guide about pediatric cardiac catheterization as a vital part of pre-procedure psychological preparation in order to reduce parental anxiety. Moreover, the educational guide can be used as a reference and disseminate it to parents before discharge.

- Conducive environment can be created in pediatric cardiac catheterization by application of verbal orientation in combining with illustrated educational guide during the orientation phase pre-procedure. 
Table (1): Percent distribution of children's characteristics

\begin{tabular}{|l|c|c|c|c||}
\hline \multirow{2}{*}{ Child characteristics } & \multicolumn{2}{c|}{ Study group } & \multicolumn{2}{c||}{ Control group } \\
\cline { 2 - 5 } & No(50) & $\%$ & No(50) & $\%$ \\
\hline Age: & 15 & $30 \%$ & 10 & $20 \%$ \\
\hline$<2$ years & 24 & $48 \%$ & 26 & $52 \%$ \\
\hline 2- 4 years & 11 & $22 \%$ & 14 & $28 \%$ \\
\hline More than 4 years & 32 & $64 \%$ & 34 & $68 \%$ \\
\hline Gender: & 18 & $36 \%$ & 16 & $32 \%$ \\
\hline Male & 38 & $76 \%$ & 40 & $80 \%$ \\
\hline Female & 12 & $24 \%$ & 10 & $20 \%$ \\
\hline Birth order: & \multicolumn{5}{|l||}{} \\
\hline First & 47 & $94 \%$ & 45 & $90 \%$ \\
\hline Second & 3 & $6 \%$ & 5 & $10 \%$ \\
\hline Diagnosis: & & & \\
\hline A-cyanotic congenital heart disease & & & \\
\hline Cyanotic congenital heart disease &
\end{tabular}


Table (2): The biosocio-demographic characteristics of parents

\begin{tabular}{|c|c|c|c|c|c|c|}
\hline Parents' Characteristics & \multicolumn{2}{|c|}{$\begin{array}{l}\text { Study } \\
\text { group } \\
(n=50)\end{array}$} & \multicolumn{2}{|c|}{$\begin{array}{l}\text { Control } \\
\text { group } \\
(\mathbf{n}=50)\end{array}$} & $\mathbf{X} 2$ & $\mathbf{P}$ \\
\hline \multicolumn{7}{|l|}{ Age/ years } \\
\hline Less than 25 & 2 & $4 \%$ & 5 & $10 \%$ & \multirow{4}{*}{9.72} & \multirow{4}{*}{0.62} \\
\hline 25 and $<30$ & 19 & $38 \%$ & 15 & $30 \%$ & & \\
\hline 30 and $<40$ & 24 & $48 \%$ & 23 & $46 \%$ & & \\
\hline 40 and above & 5 & $10 \%$ & 7 & $14 \%$ & & \\
\hline \multicolumn{7}{|l|}{ Type of parents: } \\
\hline Father & 26 & $52 \%$ & 27 & $54 \%$ & \multirow{2}{*}{0.04} & \multirow{2}{*}{0.84} \\
\hline Mother & 24 & $48 \%$ & 23 & $46 \%$ & & \\
\hline \multicolumn{7}{|l|}{ Marital Status: } \\
\hline Married & 47 & $94 \%$ & 44 & $88 \%$ & \multirow{2}{*}{9.09} & \multirow{2}{*}{0.49} \\
\hline Unmarried (divorced or widow) & 3 & $6 \%$ & 6 & $12 \%$ & & \\
\hline \multicolumn{7}{|l|}{ Level of education: } \\
\hline Elementary & 5 & $10 \%$ & 11 & $22 \%$ & \multirow{4}{*}{3.35} & \multirow{4}{*}{0.34} \\
\hline Intermediate (preparatory) & 21 & $42 \%$ & 16 & $32 \%$ & & \\
\hline Secondary & 18 & $36 \%$ & 19 & $38 \%$ & & \\
\hline University & 6 & $12 \%$ & 4 & $8 \%$ & & \\
\hline
\end{tabular}

Significant at $\mathrm{P}<0.05$ 
Table (3): Percent distribution of all parents in both groups regarding their anxiety level before giving information about pediatric cardiac catheterization

\begin{tabular}{|l|c|c|}
\hline \multirow{2}{*}{ Anxiety level } & \multicolumn{2}{|c|}{ All parents in both groups } \\
\cline { 2 - 3 } & No (100) & $\%$ \\
\hline Mild anxiety & 29 & $29 \%$ \\
\hline Moderate anxiety & 71 & $71 \%$ \\
\hline
\end{tabular}

Table (4): Level of anxiety among parents in both groups during pre-and postorientation phase

\begin{tabular}{|c|c|c|c|c|c|c|c|c|}
\hline \multirow{3}{*}{$\begin{array}{l}\text { Level of } \\
\text { anxiety }\end{array}$} & \multicolumn{4}{|c|}{ Pre-orientation phase } & \multicolumn{4}{|c|}{ Post-orientation phase } \\
\hline & \multicolumn{2}{|c|}{ Study group } & \multicolumn{2}{|c|}{ Control group } & \multicolumn{2}{|c|}{$\begin{array}{l}\text { Study } \\
\text { group }\end{array}$} & \multicolumn{2}{|c|}{ Control group } \\
\hline & $\begin{array}{l}\text { No } \\
(\mathbf{5 0})\end{array}$ & $\%$ & $\begin{array}{l}\text { No } \\
(\mathbf{5 0})\end{array}$ & $\%$ & $\begin{array}{l}\text { No } \\
(50)\end{array}$ & $\%$ & $\begin{array}{l}\text { No } \\
(50)\end{array}$ & $\%$ \\
\hline Mild anxiety & 13 & $26 \%$ & 16 & $32 \%$ & 45 & $90 \%$ & 20 & $40 \%$ \\
\hline $\begin{array}{l}\text { Moderate } \\
\text { anxiety }\end{array}$ & 37 & $74 \%$ & 34 & $68 \%$ & 5 & $10 \%$ & 30 & $60 \%$ \\
\hline & \multicolumn{4}{|c|}{$\begin{array}{l}\mathrm{X}^{2}=.437 \\
\mathrm{P}=.509\end{array}$} & \multicolumn{4}{|c|}{$\begin{aligned} \mathrm{X} 2 & =27.473 \\
\mathrm{P} & =.000^{*}\end{aligned}$} \\
\hline
\end{tabular}

Spearman chi square test $\mathrm{X}^{2}$

significant at $\mathrm{p}<0.05$

Table (5): Level of anxiety among parents in the control group during pre and post giving verbal information about cardiac catheterization

\begin{tabular}{|c|c|c|c|c|c|}
\hline \multirow{3}{*}{ Level of anxiety } & \multicolumn{4}{|c|}{ Control group } & \\
\hline & \multicolumn{2}{|c|}{$\begin{array}{c}\text { Before verbal } \\
\text { orientation }\end{array}$} & \multicolumn{2}{|c|}{$\begin{array}{c}\text { After verbal } \\
\text { orientation }\end{array}$} & \\
\hline & No (50) & $\%$ & No (50) & $\%$ & \\
\hline Mild anxiety & 16 & $32 \%$ & 20 & $40 \%$ & \\
\hline Moderate anxiety & 34 & $68 \%$ & 30 & $60 \%$ & \\
\hline Mean & \multicolumn{2}{|c|}{28.1000} & \multicolumn{2}{|c|}{23.9400} & $\begin{array}{l}\mathrm{t}=3.238 \\
\mathrm{P}=.022 *\end{array}$ \\
\hline SD & \multicolumn{2}{|c|}{8.14724} & \multicolumn{2}{|c|}{7.45164} & \\
\hline
\end{tabular}

$\mathrm{t}=$ Paired $\mathrm{t}$ test

Significant at $\mathrm{P}<0.05$ 
Table (6): Level of anxiety among parents in the study group during pre and post using the educational guide

\begin{tabular}{|c|c|c|c|c|c|}
\hline \multirow{3}{*}{ Level of anxiety } & \multicolumn{4}{|c|}{ Study group } & \\
\hline & \multicolumn{2}{|c|}{$\begin{array}{c}\text { Before using } \\
\text { educational guide }\end{array}$} & \multicolumn{2}{|c|}{$\begin{array}{c}\text { After using } \\
\text { educational guide }\end{array}$} & \\
\hline & No (50) & $\%$ & No (50) & $\%$ & \\
\hline Mild anxiety & 13 & $26 \%$ & 45 & $90 \%$ & \\
\hline Moderate anxiety & 37 & $74 \%$ & 5 & $10 \%$ & \\
\hline Mean & \multicolumn{2}{|c|}{26.1800} & \multicolumn{2}{|c|}{19.0000} & $\begin{array}{l}t=6.696 \\
P=0.00 *\end{array}$ \\
\hline SD & \multicolumn{2}{|c|}{6.2227} & \multicolumn{2}{|c|}{5.9658} & \\
\hline
\end{tabular}

Table (7): Relationship between diagnosis of the child and level of anxiety among parents in the study group

\begin{tabular}{|c|c|c|c|c|c|c|c|c|}
\hline \multirow{3}{*}{ Level of anxiety } & \multicolumn{4}{|c|}{$\begin{array}{c}\text { Study group } \\
\text { Pre orientation } \\
\text { No }(50)\end{array}$} & \multicolumn{4}{|c|}{$\begin{array}{c}\text { Study group } \\
\text { post orientation } \\
\text { No }(50)\end{array}$} \\
\hline & \multicolumn{2}{|c|}{$\begin{array}{c}\text { Cyanotic } \\
\text { congenital } \\
\text { heart disease }\end{array}$} & \multicolumn{2}{|c|}{$\begin{array}{c}\text { A-cyanotic } \\
\text { congenital } \\
\text { heart disease }\end{array}$} & \multicolumn{2}{|c|}{$\begin{array}{c}\text { Cyanotic } \\
\text { congenital } \\
\text { heart disease }\end{array}$} & \multicolumn{2}{|c|}{$\begin{array}{l}\text { A-cyanotic } \\
\text { congenital } \\
\text { heart disease }\end{array}$} \\
\hline & $\begin{array}{l}\text { No } \\
\text { (3) }\end{array}$ & $\%$ & $\begin{array}{c}\text { No } \\
\text { (47) }\end{array}$ & $\%$ & $\begin{array}{l}\text { N0 } \\
\text { (3) }\end{array}$ & $\%$ & $\begin{array}{c}\text { No } \\
\text { (50) }\end{array}$ & $\%$ \\
\hline Mild anxiety & 0 & 0 & 13 & $6 \%$ & 0 & 0 & 45 & $90 \%$ \\
\hline \multirow[t]{2}{*}{ Moderate anxiety } & 3 & $6 \%$ & 34 & $68 \%$ & 3 & $6 \%$ & 2 & $4 \%$ \\
\hline & \multicolumn{4}{|c|}{.558} & \multicolumn{4}{|c|}{$.001 *$} \\
\hline
\end{tabular}

Fisher exact test

Significance at $\mathrm{P}<0.05$

Table (8): Relationship between diagnosis of the child and level of anxiety among parents in the control group

\begin{tabular}{|c|c|c|c|c|c|c|c|c|}
\hline \multirow{3}{*}{ Level of anxiety } & \multicolumn{4}{|c|}{$\begin{array}{c}\text { Control group } \\
\text { Pre orientation } \\
\text { No }(50)\end{array}$} & \multicolumn{4}{|c|}{$\begin{array}{c}\text { Control group } \\
\text { post orientation } \\
\text { No }(50)\end{array}$} \\
\hline & \multicolumn{2}{|c|}{$\begin{array}{c}\text { Cyanotic } \\
\text { congenital } \\
\text { heart disease }\end{array}$} & \multicolumn{2}{|c|}{$\begin{array}{c}\text { A-cyanotic } \\
\text { congenital } \\
\text { heart disease }\end{array}$} & \multicolumn{2}{|c|}{$\begin{array}{c}\text { Cyanotic } \\
\text { congenital } \\
\text { heart disease }\end{array}$} & \multicolumn{2}{|c|}{$\begin{array}{c}\text { A-cyanotic } \\
\text { congenital } \\
\text { heart disease }\end{array}$} \\
\hline & $\begin{array}{l}\text { No } \\
(5)\end{array}$ & $\%$ & $\begin{array}{c}\text { No } \\
(45)\end{array}$ & $\%$ & $\begin{array}{l}\text { N0 } \\
\text { (5) }\end{array}$ & $\%$ & $\begin{array}{c}\text { No } \\
\text { (45) }\end{array}$ & $\%$ \\
\hline Mild anxiety & 4 & $8 \%$ & 12 & $24 \%$ & 4 & $8 \%$ & 16 & $32 \%$ \\
\hline \multirow[t]{2}{*}{ Moderate anxiety } & 1 & $2 \%$ & 33 & $66 \%$ & 1 & $2 \%$ & 29 & $58 \%$ \\
\hline & \multicolumn{4}{|c|}{.031} & \multicolumn{4}{|c|}{.143} \\
\hline
\end{tabular}




\section{References}

1. Uzger A, Başpına O, Bülbül F, Evaluation of depression and anxiety in parents of children undergoing cardiac catheterization. Turk Kardiyol Dern Ars 2015; 43(6): 536-41. doi: 10.5543/tkda.2015.28928.

2. Nichols DG, Ungerleider RM, Spevak PJ, Greeley WJ, Cameron DE, Lappe DG, Wetzel RC. Critical heart disease in infants and children. 2nd ed. Philadelphia: Elsevier Mosby, 2008; 1340-42.

3. Bhatt AB, Foster E, Kuehl K, Alpert J, Brabeck S, Crumb S, Davidson WR, Earing MG, Ghoshhajra BB, Karamlou $\mathrm{T}$ et al. Congenital heart disease in the older adult: A scientific statement from the American heart association. Circulation 2015; 131:1884-931.

4. Alapati, S and Rao PS. Tetralogy of Fallot in the neonate. Neonatology Today 2016; (5): 1-8

5. Ujuanbi AS, Tabansi PN, and Otaigbe BE. Heart diseases among primary school children in the Niger Delta Region of Nigeria ,West Africa Department of pediatrics, Federal Medical Centre, Nigeria. Annals of Pediatrics \& Child Health. 2016.

6. Children Heart Center. American university in Beirut Medical Center (AUBMC). 2014. Available at: http://www.aubmc.org/patientcare/spe_c li_pro_ser/Pages/chc.aspx.

7. BassiliA, Mokhtar SM A, DabousN I, and Zaki A. Congenital heart disease among school children in Alexandria, Egypt. Journal of Tropical Pediatrics. 2001; 46(6): 357-62. Available at: https://www.researchgate.net/publication 112140209 Congenital heart disease a mong_school_children_in_Alexandria_E gypt.
8. American Heart Association. Heart disease and stroke statistics-2012 update. Circulation 2012.

9. Gilboa SM, Salemi JL, Nembhard WN, Fixler DE, and Correa A. Mortality resulting from congenital heart disease among children and adults in the United States, 1999 to 2006. Circulation 2010; 122: 2254-63.

10. Hockenberry MJ, Wilson D. Wong's nursing care of infants and children. 9thed. New York: Elsevier Mosby, 2011; 1449-66.

11. Boville B, Young LC. Edward's Critical care education, Quick guide to pediatric cardiopulmonary care. Switzerland: Edwards, 2011; 25-39.

12. SCHN Policy. Procedure and guideline committee cardiac catheterization: interventional, non-interventional and electrophysiological studies-CHW, 2014.

13. Feltes TF, Bacha E, Beekman III RH, Cheatham JP, Feinstein JA, Gomes AS, Hijazi ZM, Ing FF, de Moor M, Morrow WR, Mullins CE, Taubert KA, Zahn EM. Indications for cardiac catheterization and intervention in pediatric cardiac disease: a scientific statement from the American Heart Association. Circulation. May 2011; 123: 2607-52.

14. Topol EJ, Teirtein PS. Textbook of interventional cardiology. $6^{\text {th }}$ ed. St. Louis: Saunders Elsevier, 2012; 861-94.

15. Hockenberry MJ, Perry SE. Maternal child nursing care. 5th ed. St. Louis: Elsevier Mosby, 2014; 1109-25.

16. Woolf - King SE, Anger A, Arnold EA, Weiss SJ, Teitel D. Mental health among parents of children with critical congenital heart defects: A Systematic Review. Journal of the American Heart Association 2017; 6(2): e004862 DOI: 10.1161/JAHA.116.004862. 
17. American Psychiatric Association. Diagnostic and Statistical Manual of Mental Disorders. $5^{\text {th }}$ ed: (DSM-V). 2013.

18. Buzatto LL, Zanei SSV. Patients' anxiety before cardiac catheterization. Einstein (São Paulo) 2010; 8(4). Online version ISSN 2317-6385. Available at: $\quad$ http://dx.doi.org/10.1590/s1679$\underline{45082010 \mathrm{rw} 1517 .}$.

19. LeRoy S, Elixson EM, O'Brien P, Tong E, Turpin S, Uzark K. Recommendations for preparing children and adolescents for invasive cardiac procedures: a statement from the American Heart Association pediatric nursing subcommittee of the council on cardiovascular nursing in collaboration with the council on cardiovascular diseases of the young. Circulation. 2003; 108:2550-64.

20. Utens EM, Versluis-Den Bieman HJ, Verhulst FC, et al. Psychological distress and styles of coping in parents of children awaiting elective cardiac surgery. Cardiol Young. 2000; 10: 239 44.

21. Gilmer $\mathrm{C}$ et al. Parent education interventions designed to support the transition to parenthood: a realist review. International Journal of Nursing Studies 2016; 59:118-33.

22. Dunst C, Hamby D. Tailoring printed materials for improving child find. Practice-Based Research Syntheses of Child Find, Referral, Early Identification, and Eligibility Practices and Models 2006; 2 (4):1-11.

23. Wilson E et al. Media and memory: the efficacy of video and print materials for promoting patient education about asthma. Patient Education and Counseling 80 2010; 80: 393-8.

24. Wilson E et al. Comparative analysis of print and multimedia health materials: a review of the literature. Patient Education and Counseling 2012; 89: 7 14.

25. Paul C, Redman S, Fisher S. Print material content and design: is it relevant to effectiveness? Health Education Research 2003; 18 (2): 181-90.

26. Griffin J, McKenna K, Tooth L. Written health education materials: making them more effective. Australian Occupational Therapy Journal 2003; 50: 170-7.

27. GathoniK ,Magembe O. Utilization of mother and child booklet among mothers attending well baby clinic in Nakuru central district. International Journal of Science and Research 2015;4(4):2642-8.

28. Beck AT, Epstein N, Brown G, Steer, R. A. Aninventory for measuring clinical anxiety: Psychometric properties. Journal of Consulting and Clinical Psychology, 1988; 56: 893-7.

29. Beekman RH, Hellenbrand WE, Lloyd TR, Lock JE, Mullins CE, Rome JJ, Teitel DF. Task Force 3: Training guidelines for pediatric cardiac catheterization and interventional cardiology. Journal of the American College of Cardiology 2005; 46(7):138890.

30. Stanford children health. Cardiac Catheterization in Children. Available at http://www.stanfordchildrens.org/en/topi c/default?id=cardiac-catheterization-inchildren-90-P01772.

31. Atwa ZT, Safar HH. Outcome of congenital heart diseases in Egyptian children: Is there gender disparity? Egyptian Pediatric Association Gazette 2014; 62(2):35-40.

32. Abou heba MGM, Effect of early ambulation following cardiac catheterization on health parameters of children with congenital heart defects. Unpublished Doctoral Dissertation. 
Faculty of nursing, Alexandria University. Egypt 2015.

33. Majdalani MN, Doumit MA, Rahi AC. The lived experience of parents of children admitted to the pediatric intensive care unit in Lebanon. Int $\mathbf{J}$ Nurs Stud. Feb 2014; 51(2):217-25. doi: 10.1016/j.ijnurstu.2013.06.001. Epub 2013 Jun 28.

34. Countries and their culture. Available at: http://www.everyculture.com/JaMa/Lebanon.html

35. Shan CH, Hawkins R. Childcare and parenting practices in Singapore: A comparison of fathers' and mothers' involvement. Journal of tropical psychology 2014; 4(e10). DOI: https://doi.org/10.1017/jtp.2014.10

36. http://family.jrank.org/pages/439/EgyptGender-Family.html.

37. Składzień T, Górecka K, Wiśniowski Z, Jaworska I, Wójcik E, Mroczek T, Skalski J. Anxiety, depressiveness and irritability in parents of children treated surgically for congenital heart defects. Kardiochirurgiai Torakochirurgia Polska 2011; 4: 479-82.

38. Chessa, M., DeRosa, G., Pardeo, M., Negura, D. G.,Butera, G., Giambetri, A, et al. What doparents know about the malformations afflicting thehearts of their children? Cardiology in the Young, 2005; 15,125-9

39. Carey LK, Nicholson BC, Fox RA. Maternal factors related to parenting young children with congenital heart disease. Journal of Pediatric Nursing, 2002, 17, 174-83.

40. Rahimianfar AA, Forouzannia S K, Sarebanhassanabadi M, Dehghani $H$, Namayandeh SM, Khavary Z, Rahimianfar F, Aghbageri H. Anxiety determinants in mothers of children with congenital heart diseases undergoing cardiac surgery. Advanced Biomedical Research 2015; 4:255. Doi: 10.4103/2277-9175.170680.

41. Zahrlk. Therapeutic play for hospitalized preschool in Lebanon. Pediatric nursing 2004; 23(5): 449-54.

42. Mattie-Luksic M, Javornisky G, DiMario FJ. Assessment of stress in mothers of children with severe breathholding spells. Pediatrics 2000;106: 1-5.

43. Chan DS, Cheung HW. The effects of education on anxiety among Chinese patients with heart disease undergoing cardiac catheterization in Hong Kong. Contemp Nurse 2003; 15(3):310-20.

44. Philippe F, Meney M, Larrazet F, Ben Abderrazak F, Dibie A, Meziane T et al. Effects of video information in patients undergoing coronary angiography. Arch Mal Coeur Vaiss 2006; 99(2):95-101.

45. Valizadeh L, Hosseini M B, Damanabad ZH, Farshi MR, Jafarabadi MA, Kochaksaraie FR. Effect of NICU Department Orientation Program on Mother's Anxiety: a Randomized Clinical Trial. J Caring Sci. Sep 2016; 5(3): 205-14.

46. Naylor D, Coates JT, Kan J. Reducing distress in pediatric cardiac catheterization. Am J Dis Child. 1984; 138(8):726-9. doi: 10.1001/archpedi.1984.0214046001800.

47. Karten C. Easy to write? Creating easy to read patient education materials. Clin J Oncol Nurs.2007; 11(4):506-10. doi: 10.1188/07.CJON.506-510.

48. Ayasrah S, Ahmad M. Educational video intervention effects on periprocedural anxiety levels among cardiac catheterization patients: A randomized clinical trial. Research and theory for nursing practice February 2016; 30(1). doi: 10.1891/1541-6577.30.1.70 
49. Ruffinengo C, Versino E, Renga G. Effectiveness of an informative video on reducing anxiety levels in patients undergoing elective coronarography: an RCT. Eur J CardiovascNursMar 2009; 8(1):57-61.

doi:

10.1016/j.ejcnurse.2008.04.002. Epub 2008 May 27.

50. Harkness K, Morrow L, Smith K, Kiczula M, Arthur MH. The effect of early education on patient anxiety while waiting for elective cardiac catheterization. J Cardiovasc Nurs 2003; 2(2):113-21.

51. Reberte LM, Hoga LAK, Gomes ALZ. Process of construction of an educational booklet for health promotion of pregnant women. Revista Latino-Americana de Enfermagem. 2012; 20(1):101-8. doi: 10.1590/S0104-11692012000100014.

52. Mullin CE. Cardiac catheterization and imaging from pediatrics to geriatrics. Jaypee Brother's medical publishers $(\mathrm{P})$ Ltd. 2015; 55.

53. Kunst H, Groot D, Latthe PM. Accuracy of information on apparently credible websites: survey of five common health topics. BMJ. 2002; 324: 581-2. 